\title{
UJI EKSPERIMENTAL STABILISASI TANAH LEMPUNG DENGAN AMPAS BATU GAMPING INDUSTRI MARMER
}

\author{
Indriyanti ${ }^{1)}$ Kasmawati $^{2)}$ \\ ${ }^{1}$ Universitas Muhammadiyah Makassar, Indonesia \\ Email:indriyanti.azis@gmail.com \\ ${ }^{2}$ Universitas Muhammadiyah Makassar, Indonesia \\ Email :kasma80508@rocketmail.com
}

\begin{abstract}
ABSTRAK
Stabilisasi kimiawi pada tanah lempung biasanya memakai bahan semen atau kapur, pada penelitian ini digunakan serbuk marmer hasil limbah olahan industri pemotongan marmer dan larutan asam akrilat. Penelitian ini bertujuan untuk menganalisis karakteristik limbah marmer. Menganalisis kekuatan tanah lempung sebelum dan sesudah distabilisasi dengan limbah marmer (serbuk marmer), menganalisis pengaruh asam akrilat sebagai cairan aktivator stabilisasi tanah lempung dengan serbuk marmer, serta mengetahui mikrostruiktur tanah setelah distabilisasi dengan serbuk marmer dan larutan asam akrilat. Pengujian laboratorium dilakukan dengan metode pengujian pencampuran serbuk marmer 5\%-30\% terhadap tanah lempung dan untuk pengujian dengan larutan asam akrilat 5\%-15\% terhadap campuran air. Pengujian mikrostruktur tanah menggunakan SEM dan XRDyang dicampurkan kedalam sampel tanah, semakin meningkatkan nilai CBR (20\%-30\% serbuk marmer, CBR > 6\%). Untuk pengujian UCS penambahan larutan asam akrilat pada kadar optimum serbuk marmer dan dilakukan pemeranam 3 dan 7 hari, terjadi peningkatan kekuatan tanah menjadi konsistensi medium. Kandungan senyawa pada serbuk marmer adalah $\mathrm{CaO}$ 97,15\% lebih dominan kandungan kapurnya yang merupakan bahan efektif untuk stabilisasi tanah lempung. Hal ini menunjukkan bahwa campuran serbuk marmer dan larutan asam akrilat sebagai bahan stabilisasi untuk tanah lempung dapat meningkatkan daya dukung tanah untuk subgrade pada konstruksi jalan.
\end{abstract}

Kata kunci : Tanah lempung, serbuk marmer, asam akrilat, CBR dan UCS.

\begin{abstract}
Chemical stabilization on clay usually wear cement or lime, in this research used to the results of waste processed marble dust from waste cutting marble industry and of acrylic acid. This research aimed to analyze the characteristics of marble dust. To analyze the strengths of the clay before and after it was stabilized with the marble dust, to analyze the effect of the acrylic acid as the liquid activator of the clay soil stabilization with marble dust, and to analyze soil microstructure after it was stabilized with marble dust and acrylic acid.The laboratory test was conducted using the method of the mixture of the marble dusts of 5\%-30\% and acrily acid of 5\% $-15 \%$ mixed with water. The test of the soil microstrukture used SEM and XRD. The test result of the mechanistic characteristic (CBR and UCS) indicated that in general, the more marble dusts was added into the soil sample, the higher was the value of CBR $(20 \%-30 \%$ of the marble dust, $C B R>6 \%)$. For the test of UCS, the addition of the acrilyc acid to the optimum level of the marble dusts was $\mathrm{CaO} 97,15 \%$ showed that its chalk content was more dominant, wich proved to be an effective material to stabilize the clay soil.. This shows that a mixture of marble dust and acrylic acid as stabilizing agent for the clay can increase the carrying capacity of the soil for subgrade for road construction.
\end{abstract}

Keywords : Clay, marble dust, acrilyc acid, CBR and UCS 


\section{PENDAHULUAN}

Stabilisasi tanah atau perbaikan tanah yang dikenal dalam rekayasa geoteknik secara umum terbagi dalam tiga kategori, yaitu cara mekanis, cara kimia, dan cara fisik. Cara mekanis didasarkan atas usahausaha mekanis, seperti kompaksi dan konsolidasi. Melalui cara yang paling umum digunakan kerapatan tanah akan meningkat, kompresibilitas tanah berkurang, yang kemudian diikuti pula dengan peningkatan kapasitas daya dukung dan stabilitas tanah. Pada cara kimiawi, suatu bahan aditif berupa binders (semen, kapur, abu terbang) dicampurkan dalam tanah yang kemudian akan mengubah propertis dan kekuatan tanah. Sedangkan pada cara fisik, suatu bahan perkuatan seperti geotekstil dimasukkan atau disusun pada lapisan tanah untuk memperkuat tanah, (Zultan, 2011).

Pada dasarnya marmer mempunyai unsur dominan yang sama dengan kapur. Batuan marmer asalnya juga adalah batuan kapur yang kemudian mengalami proses metamorfosa batuan. Meskipun unsurnya sama, bangun kristal marmer tidak sama dengan batu kapur biasa. Selain itu setelah mengalami proses metamorfosa batuan selama berpuluh-puluh tahun, tentunya ada beberapa perubahan sifat dari batuan marmer dibanding batuan kapur. Jadi mungkin sifat reaktif marmer terhadap tanah lempung juga berbeda. Menurut Zulkifli, dkk (2010), dari hasil analisis kimia limbah marmer menunjukkan kandungan Kalsium Oksida yang paling besar, diatas 50 $\%$. Dengan kandungan Kalsium Oksida $(\mathrm{CaO})$ yang terdapat pada limbah marmer memungkinkan akan memiliki peranan sebagai material pozzolan yang ditambahkan dengan tanah lempung.

Berbagai penelitian telah dilakukan sebelumnya antara lain: Wardana (2009), Kelakuan Tanah Dengan Sifat Kembang Susut Yang Tinggi Pada Stabilisasi Tanah dengan Bahan Serbuk Marmer dan Stabilia, penelitian ini menggunakan serbuk marmer dan bahan stabilia sebagai bahan stabilisasi tanah lempung untuk mengetahui perubahan plastisitas tanah serta nilai swelling. Selanjutnya penelitian Baser (2009), Stabilization of Expansive Soils Using Waste 
Marble Dust, dalam penelitian penambahan serbuk marmer $0-30 \%$ pada tanah ekspansif untuk mengetahui pengaruh nilai PI dan swelling setelah dilakukan pemeraman selama 7 hari. Penelitian agrawal \& Mohit (2011), Expansive Soils Stabilization Using Marble Dust, dalam penelitian ini digunakan serbuk marmer sebagai bahan stabilisasi tanah ekspansif dengan campuran 0-30\% serbuk marmer dan dilakukan pemeraman 7 dan 28 hari untuk mengetahui pengaruh terhadap plastisitas tanah dan swelling.

Penelitian ini bertujuan untuk menganalisis karakteristik limbah hasil olahan industri marmer dan tanah lempung, menganalisis kekuatan tanah lempung sebelum dan sesudah distabilisasi dengan limbah marmer (serbuk marmer), menganalisis pengaruh asam akrilat sebagai cairan aktivator stabilisasi tanah lempung dengan serbuk marmer, menganalisis hasil pengujian minerologi setelah pencampuran tanah lempung dengan serbuk marmer dan larutan asam akrilat.
BAHAN DAN METODE

\section{Lokasi dan Rancangan Penelitian}

Penelitian ini dilakukan di Laboratorium Mekanika Tanah Jurusan Teknik Sipil, Fakultas Teknik, Universitas Hasanuddin. Pemerikasaan meliputi pemeriksaan sifat fisis dan mekanis tanah. Tanah lempung yang digunakan dalam penelitian ini berasal dari tanah asli pada $\mathrm{km} \quad 546+500$ perbatasan Kabupaten Sidrap dan Kabupaten Wajo. Serbuk marmer yang digunakan berasal dari limbah olahan industri pemotongan marmer di Kabupaten Enrekang. Dalam pengujian sifat fisis dan mekanis tanah digunakan standart SNI dan ASTM sesuai dengan jenis pengujian yang dilakukan. Rancangan penelitian yang di gunakan dalam penelitian ini merupakan metode experimental yang dilakukan di labolatorium.

\section{Metode Pengumpulan Data}

Pengumpulan data dilakukan dengan melakukan penelitian awal yaitu pengujian komposisi kimia serbuk marmer dan tanah untuk mengetahui unsur-unsur dominan penyusun tanah lempung $\left(\mathrm{Al}_{2} \mathrm{O}_{3}\right.$ dan 
$\mathrm{SiO}_{2}$ ) untuk menentukan apakah tanah lempung yang akan diteliti benar-benar merupakan tanah lempung ekspansif atau merupakan lempung biasa. Pengujian kedua meliputi: Pengujian analisis saringan digunakan standar SNI 03-1968-1990 dan SNI 03-3423-1994, yaitu dengan nomor saringan : 10,20,40,60, 140, dan 200, serta hidrometer, Pengujian indeks properties menggunakan standar SNI 03-1967-1990, SNI 031964-2008/ASTM D854-88(72) dan ASTM D 2216-71. Pengujian sifat mekanik tanah asli meliputi, uji kompaksi (SNI 03-1742-1989 atau SNI 03-1744-1989), CBR (SNI 031744-1989), serta kuat tekan bebas (SNI 03-3638-1994 / ASTM D 2166). Pengujian lanjutan: Pengujian CBR menggunakan standard SNI 031744-1989. Tanah asli pada percobaan sebelumnya ditambah dengan serbuk marmer dengan prosentase : 5,10,15,20,25, dan 30\%, pengujian ini dilakukan pada kondis tidak terendam. Pengujan kuat tekan bebas dilakukan dengan komposisi Tanah + serbuk marmer, dengan pemeraman 7 hari. Pengujian ini menggunakan standar SNI 03-3638-
1994 / ASTM D 21-66, untuk campuran tanah, serbuk marmer dan asam akrilat (5,7,10,12 dan 15\%) dengan pemeraman 3 dan 7 hari.

\section{HASIL}

\section{Hasil Pengujian Kimia Tanah}

\section{Lempung dan Limbah Marmer}

Hasil pengujian analisis kimia yang dilakukan pada Laboratorium Miksrostruktur UNM pada tanah lempung diperoleh senyawa yang dominan yaitu $\mathrm{SiO}_{2}=59,73 \%$ dan $\mathrm{Al}_{2} \mathrm{O}_{3}=21,18 \%$ (tabel 1). Serbuk marmer Kabupaten Enrekang, memiliki kandungan $\mathrm{CaO}=97,15 \%$ : $\mathrm{MgO}=1,47 \%: \mathrm{Al}_{2} \mathrm{O}_{3}=0,28 \%: \mathrm{K}_{2} \mathrm{O}$ $=0,82 \%:$ dan $\mathrm{SiO}_{2}=0,28 \%$. Senyawa yang dominan adalah kalsium oksida.

\section{Hasil Pengujian sifat Fisis dan Mekanis TanahAsli}

Hasil pengujian tanah lempung yang diambil dari Kabupaten Wajo, yang digunakan dalam penelitian ini diperoleh kadar air natural sampel 45,1\% dengan berat jenis 2,63. Pengujian batasbatas Atterberg menunjukkan batas cair (liquid limit) yang dihasilkan dari grafik hubungan jumlah ketukan dan 
kadar air diperoleh nilai batas cair $(\mathrm{LL})=79,07 \%$, batas plastis (plastic limit) dari hasil pengujian diperoleh hasil $(P L)=20.03 \%$. Dan Indeks plastisitas yang diperoleh dari selisih antara batas cair dan batas plastis $\mathrm{PI}=$ $59,04 \%$ sementara batas susut (Shringkage Limit, SL) diperoleh nilai batas susut $=6,76 \%$.

\section{Tabel 1. Hasil uji Difraksi Sinar-X}

\begin{tabular}{ccccc}
\hline Senyawa & $\begin{array}{c}\text { Tanah asli } \\
(\%)\end{array}$ & $\begin{array}{c}\text { Serbuk } \\
\text { Marmer } \\
(\%)\end{array}$ & $\begin{array}{c}\text { Tanh + Serbuk } \\
\text { Marmer }\end{array}$ & $\begin{array}{c}\text { Tanah }+ \\
\text { Serbuk Marmer }+ \\
\text { Asam Akrilat }\end{array}$ \\
\hline $\mathrm{SiO}_{2}$ & 59.73 & 0.28 & 48.37 & 35.92 \\
$\mathrm{AlO}_{3}$ & 21.18 & - & - & - \\
$\mathrm{NaO}_{2}$ & 3.96 & - & - & - \\
$\mathrm{MgO}$ & 3.5 & 1.47 & - & - \\
$\mathrm{K}_{2} \mathrm{O}$ & 0.13 & 0.83 & 2.07 & 2.22 \\
$\mathrm{CaO}$ & 3.98 & 97.15 & 27.26 & 36.66 \\
$\mathrm{TiO}$ & 0.42 & - & 1.04 & - \\
$\mathrm{FeO}$ & 6.18 & - & - & - \\
$\mathrm{NiO}$ & 0.25 & - & - & - \\
$\mathrm{Al}_{2} \mathrm{O}_{3}$ & - & 0.28 & 8.84 & 7.69 \\
$\mathrm{Fe}_{2} \mathrm{O}_{3}$ & - & - & 12.26 & 12.16 \\
$\mathrm{SO}_{3}$ & - & - & - & 3.71 \\
\hline
\end{tabular}

Analisa gradasi butiran menunjukkan $63,6 \%$ tanah berbutir halus dan 36,4\% tanah berbutir kasar. Dari hasil uji pemadatan standar juga diketahui tingkat kepadatan maksimum diperoleh pada kadar air optimum ( $\mathrm{w}_{\mathrm{opt}}$ ) sebesar $27 \%$ dan berat isi kering ( ddmaks) maksimumnya 1,43 $\mathrm{gr} / \mathrm{cm}^{3}$. Hasil uji CBR tanah asli dengan nilai CBR desain yaitu $2,83 \%$. Pengujian kuat tekan bebas dengan hasil yang didaptkan yaitu 0,009 $\mathrm{kg} / \mathrm{cm} 2$. Hasil pengujian dapat dilihat pada tabel 2 . 
Tabel 2. Hasil pengujian sifat fisis dan mekanis tanah

\begin{tabular}{llcc}
\hline No & \multicolumn{1}{c}{ Jenis Pengujian } & Hasil Pengujian & Satuan \\
\hline 1. & Pengujian Kadar Air & 45,1 & $\%$ \\
2. & Pengujian Berat Jenis & 2,63 & - \\
3. & Pengujian Analisa Saringan & & \\
& a. Berbutir Kasar & 36,4 & $\%$ \\
& b. Berbutir Halus & 63,6 & $\%$ \\
4. & Batas - Batas Atterberg & 79,07 & $\%$ \\
& a. Batas Cair & 20,03 & $\%$ \\
& b. Batas Plastis & 59.04 & $\%$ \\
& c. Indeks Plastisitas & 6,76 & $\%$ \\
5. Batas Susut & CBR Desain & 2,83 & $\%$ \\
6. & Kuat Tekan Bebas & 0,109 & $\mathrm{Kg} / \mathrm{cm}^{2}$ \\
\hline
\end{tabular}

Hasil Pengujian Mekanis Setelah

Pencampuran dengan Serbuk

Marmer

Hasil pengujian CBR

campuran tanah lempung dan serbuk

marmer dengan prosentase campuran serbuk marmer 5, 10, 15, 20, 25, dan 30\% diperoleh nilai CBR tertinggi pada campuran serbuk marmer $30 \%$ dengan nilai CBR desain yaitu $7,59 \%$. Hasilnya dapat dilihat pada gambar 1 .

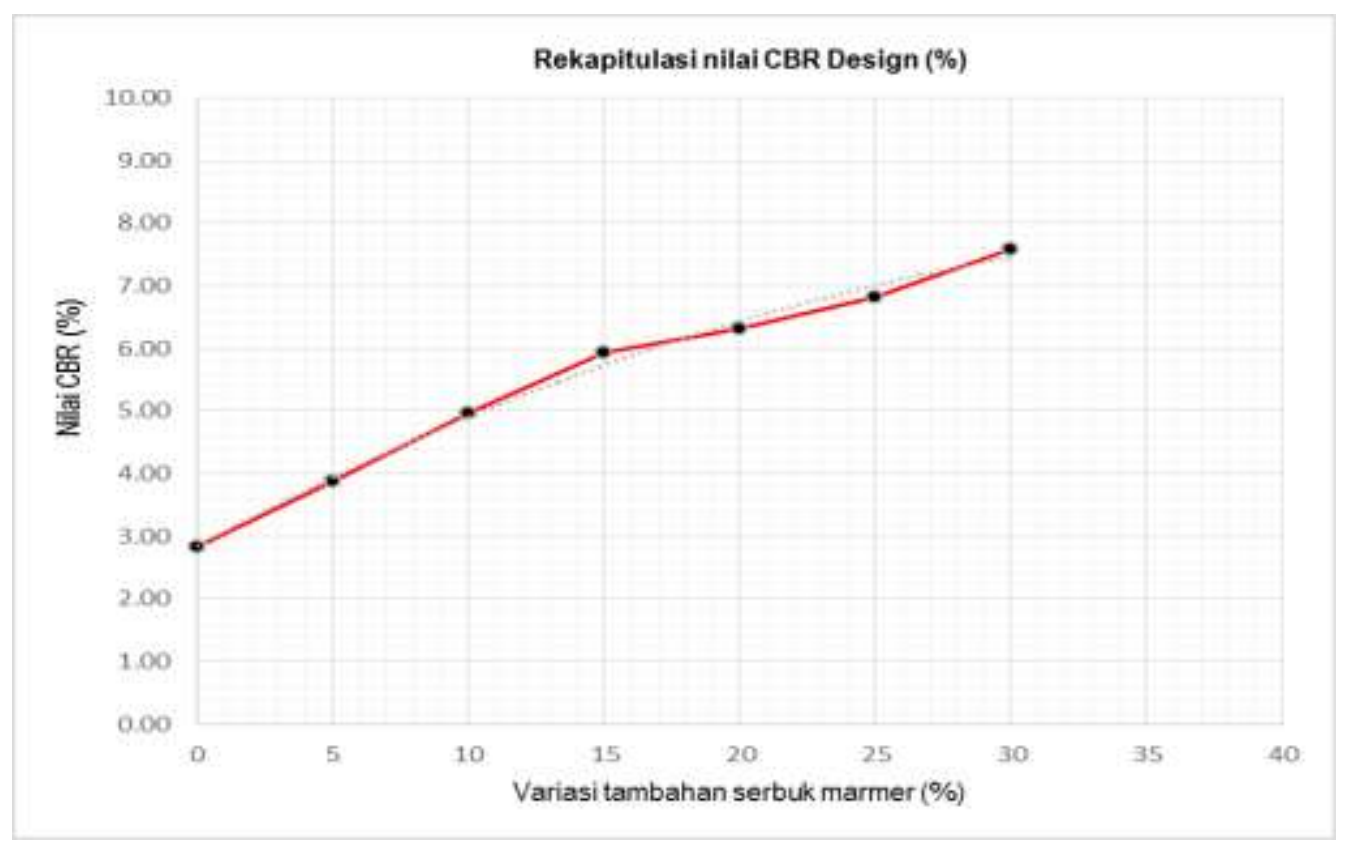

Gambar 1. Hasil uji CBR tanah dan serbuk marmer 
Hasil pengujian kuat tekan bebas (UCS), dengan campuran serbuk marmer 5, 10, 15, 20, 25 dan $30 \%$ dengan pemeraman 0 dan 7 hari diperoleh nilai tertinggi pada campuran 30\% serbuk marmer yaitu $0,45 \mathrm{~kg} / \mathrm{cm}^{2}$. Hasilnya dapat dilihat pada gambar 2 .

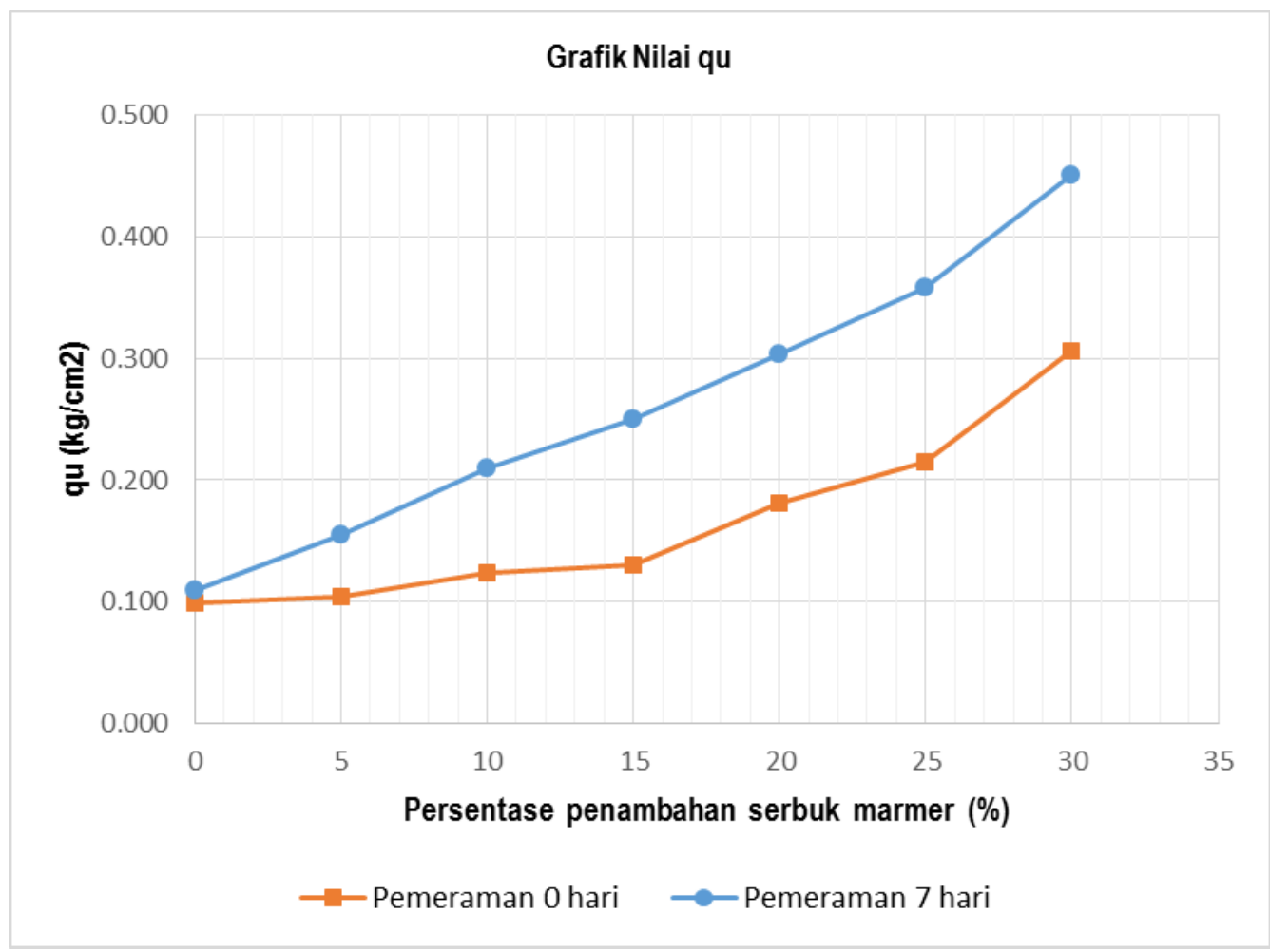

Gambar 2. Hasil uji UCS tanah dan serbuk marmer

Hasil Pengujian Mekanis Setelah Pencampuran dengan Serbuk

\section{Marmer dan Asam Akrilat}

Hasil pengujian UCS dengan serbuk marmer diperoleh kadar campuran dengan hasil yang maksimal, lalu ditambahkan dengan larutan asam akrilat dengan prosentase dari campuran air 5, 7, 10,
13 dan 15\%, dengan masa pemeraman 3 dan 7 hari. Hasil yang diperoleh setelah penambahan larutan asam akrilat $15 \%$ dan masa pemeraman 3 hari yaitu $0,671 \mathrm{~kg} / \mathrm{cm}^{2}$ sedangkan untuk pemeraman 7 hari $0,758 \mathrm{~kg} / \mathrm{cm}^{2}$. Hasilnya dapat dilihat pada gambar 3 . 


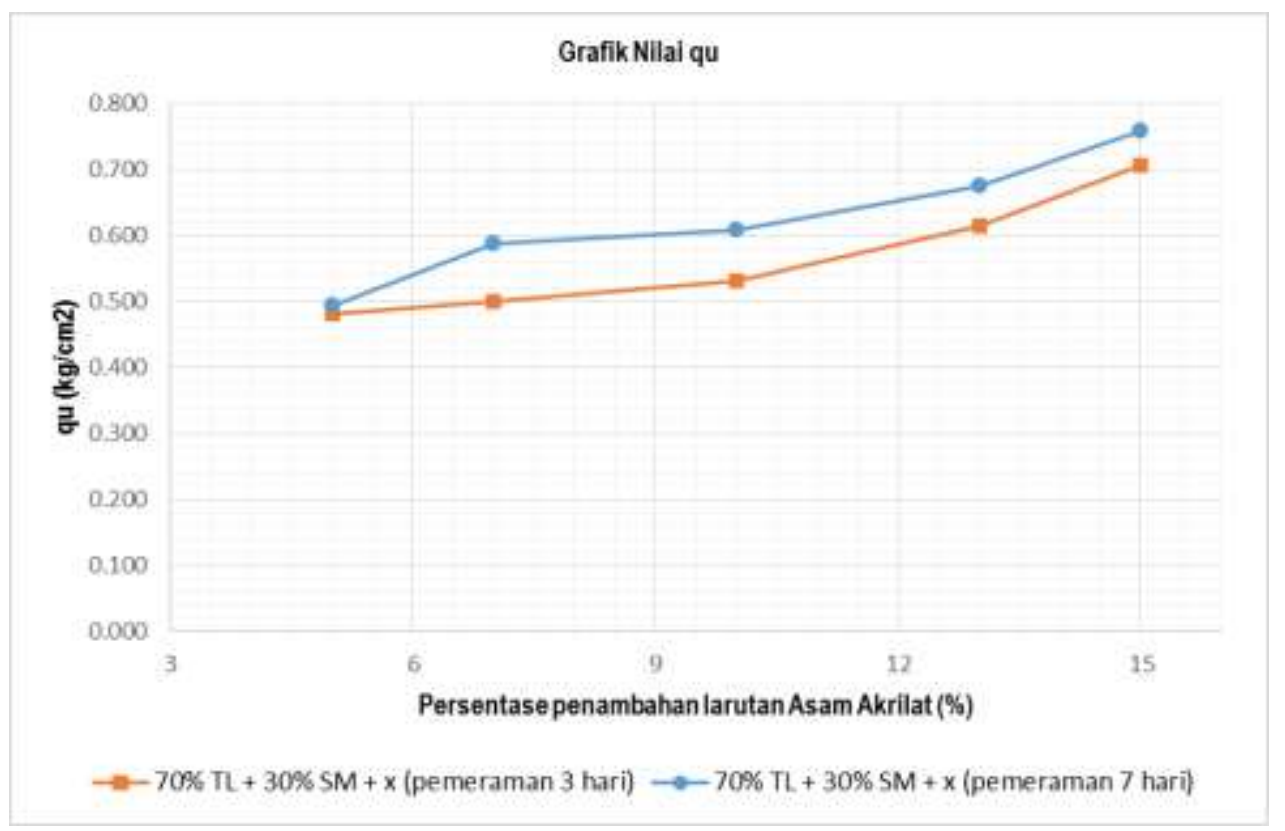

\section{Gambar 3. Hasil uji UCS tanah, serbuk marmer dan larutan asam akrilat}

Hasil Pengujian Difraksi Sinar-X

dengan Serbuk Marmer dan

Larutan Asam Akrilat

Hasil pengujian Difraksi

Sinar-X memperlihatkan bahwa untuk senyawa $\mathrm{SiO}_{2}$ pada campuran $70 \%$ tanah lempung dan 30\% serbuk marmer adalah $48,37 \%$. Untuk senyawa $\mathrm{CaO}$ yaitu $27,26 \%$. Sedangkan pada campuran $70 \%$ tanah lempung, 30\% serbuk marmer dan $15 \%$ larutan asam akrilat terhadap air, senyawa $\mathrm{SiO} 2$ yang diperoleh adalah $35,92 \%$ dan $\mathrm{CaO}$ 36,66\%. Hasil selengkapnya pada tabel 1 .

\section{PEMBAHASAN}

Berdasarkan analisis kimia pada serbuk marmer bahwa senyawa Kalsium Oksida $(\mathrm{CaO})$ lebih dominan dari senyawa lain. Sama halnya seperti senyawa dominan yang terdapat dalam kapur dan semen, yang digunakan dalam stabilisasi tanah lempung. $\mathrm{CaO}$ ini merupakan senyawa yang dibutuhkan dalam proses kimiawi dengan tanah lempung, yang akan menghasilkan ion-ion kalsium tinggi yang dapat mengikat dan berada di sekeliling partikel-partikel tanah lempung 
sehingga dapat mengurangi tarikan terhadap air. (Al Huda \& Gunawan, 2013).

Menurut USCS, tanah termasuk berbutir halus, ini dinyatakan dengan persen lolos saringan 200 lebih dari $50 \%$. Nilai batas cair yang diperoleh lebih dari 50 $\%$ menyebabkan tanah memiliki plastisitas tinggi. Dari hasil pengklasifikasian tanah berdasarkan USCS maka sampel tanah lempung termasuk ke dalam jenis tanah lempung tak organik dengan plastisitas tinggi $(\mathrm{CH})$. Sedangkan menurut AASHTO sampel tanah lempung termasuk tanah kelompok A-7-6 yang ditentukan berdasarkan persen lolos saringan 200 lebih dari $35 \%$, nilai batas cair lebih dari $41 \%$, nilai indeks plastisitas lebih dari $11 \%$ dan nilai batas plastis kurang dari 30 $\%$, (Hardiyatmo, 2006).

Pengujian pemadatan standar (proctor standard test) didapat hasil dari grafis dimana kadar air optimum sebesar $\mathrm{w}_{\mathrm{opt}}=27 \%$ dan berat isi kering maksimumnya $\gamma_{\mathrm{dmaks}}=1,43$ gram $/ \mathrm{cm}^{3}$. Dari hasil pemeriksaan kuat tekan bebas tanah dasar di peroleh nilai qu $=0.099 \mathrm{~kg} / \mathrm{cm}^{2}$, yang menandakan bahwa tanah lempung tersebut berada pada kondisi konsistensi sangat lunak. Nilai CBR desain dari hasil pengujian CBR unsoaked adalah 2,83\% sangat tidak memenuhi sebagai syarat subgrade untuk konstruksi jalan, (Hardiyatmo, 2010).

Hasil dari pengujian CBR tanah lempung dengan campuran serbuk marmer seiring dengan penambahan persentase serbuk marmer telah meningkatkan nilai daya dukung tanah pada sampel tanah lempung. Naiknya nilai CBR ini disebabkan penambahan campuran serbuk marmer akan mengisi rongga pori tanah menyebabkan saling mengunci antara butir-butirnya, selain itu disebabkan terjadinya reaksi pozzolan antara serbuk marmer memperkuat ikatan antar partikel, dimana kalsium oksida pada serbuk marmer yang dihasilkan pada waktu dehidrasi akan membentuk reaksi dengan tanah yang menyebabkan terbentuknya massa tanah yang keras dan kaku sehingga tanah menjadi keras dan saling mengunci antara satu dengan yang lainnya, (Wiqoyah, 2006). 
Pengujian kuat tekan bebas dilakukan dengan prosentase campuran serbuk marmer terhadap tanah 5, 10,15, 20, 25 dan 30\%. Dengan penambahan serbuk marmer terhadap tanah menunjukkan kecenderungan adanya peningkatan nilai qu. Demikian pula pada campuran tanah lempung, serbuk marmer dan larutan asam akrilat memperlihatkan adanya peningkatan nilai qu seiring dengan penambahan jumlah larutan asam akrilat. Hal ini diakibatkan karena meningkatnya ikatan antar butiran karena proses semenisasi, rongga-rongga pori yang ada akan dikelilingi bahan sementasi yang lebih keras, sehingga butiran tidak mudah hancur atau berubah bentuk, (Hasanuddin, 2011).

Demikian halnya, dengan bertambahnya waktu pemeraman, kenaikan yang cukup besar terjadi pada waktu pemeraman 7 hari. Kenaikan nilai kuat tekan bebas pada tanah lempung, setelah pencampuran dengan serbuk marmer dan larutan asdam akrilat mencapai $85,62 \%$, hal tersebut disebabkan oleh dua hal, yaitu : Pertama, terjadinya pertukaran ion-ion positif (kation) yang ada didalam tanah lempung $(\mathrm{Na}+$ dan $\mathrm{K}+)$ oleh ion ion positif yang ada didalam kapur (Ca++). Reaksi pertukaran ionion postif ini terjadi dalam waktu yang relatif singkat dan akan menyebabkan proses terjadinya butiran-butiran yang cukup besar (flokulasi). Oleh membesarnya butiran-butiran tanah lempung akan menaikkan nilai sudut gesek dalam tanah tersebut yang berakibat pada kenaikan kuat geser tanah (dalam hal ini kuat tekan bebas). Karena singkatnya reaksi tersebut, pada masa pemeraman yang relatf singkat terjadi kenaikan kuat tekan bebas yang sangat berarti. Kedua, terjadinya reaksi posolanik yaitu reaksi pembentukan calsium silikat hidrat (C-S-H) atau calsium silikat aluminat hidrat (C-S-A-H) oleh terjadinya ikatan antara $\mathrm{CaO}$ ditambah air ditambah $\mathrm{Al}_{2} \mathrm{O}_{3}$ dan $\mathrm{SiO}_{2}$ yang ada didalam serbuk marmer. Proses ini lebih dibuktikan lagi berdasarkan hasil pengujian Difraksi Sinar-X yang telah dilakukan. Hidrat-hidrat tersebut berbentuk gel dan akan mengeras dalam kurun waktu tertentu, (Sutikno \& Damianto, 2009). 


\section{KESIMPULAN \& SARAN}

Dari hasil penelitian pengujian karakteristik fisik, mekanik serta kimia terhadap tanah asli yang merupakan tanah lempung ekspansif. Serbuk marmer memiliki kandungan $\mathrm{CaO} 97,15 \%$. Karakteristik melalui uji CBR dengan penambahan serbuk marmer dapat menyebabkan peningkatan daya dukung tanah dan telah memenuhi nilai CBR untuk subgrade konstruksi jalan (lebih besar dari 6\%). Melalui uji kuat tekan bebas, kekuatan tanah yang dihasilkan semakin meningkat seiring dengan penambahan serbuk marmer. Dengan penambahan 30\% marmer terhadap tanah asli dan lama pemeraman 7 hari diperoleh nilai qu $0,45 \mathrm{~kg} / \mathrm{cm}^{2}$ pada konsistensi soft. Selanjutnya dengan tambahan campuran serbuk marmer (30\%) dan larutan asam akrilat (15\%) dengan masa pemeramana 7 hari nilai qu yang diperoleh $0,758 \mathrm{~kg} / \mathrm{cm}^{2}$ sehingga kekuatan tanah berubah menjadi konsistensi medium. Hasil pengujian Difraksi Sinar-X dengan cara SEM dan XRD menunjukkan campuran tanah lempung serbuk marmer Kabupaten Enrekang dan larutan asam akrilat, yang mana unsur-unsur kimia yang terkandung didalam bahan stabilisasi $(\mathrm{CaO})$ menyatu dengan tanah (SiO2) akan mengalami proses pozzolan sehingga tanah lempung lebih mengeras yang menyebabkan daya dukung tanah lempung meningkat. Dalam pengujian dan analisa pada penelitian ini ada terdapat beberapa saran untuk melengkapi kekurangan-kekurangan yang dialami antara lain, perlu diadakan penelitian lanjutan penambahan serbuk marmer dengan variasi yang berbeda dan masa pemeraman hingga 28 hari terhadap tanah yang distabilisasi untuk memperoleh ikatan yang lebih kuat antara tanah asli dengan bahan stabilisasi. Selain itu perlu peninjauan dari segi aspek lingkungan terhadap bahan stabilisasi yang digunakan.

\section{DAFTAR PUSTAKA}

Agrawal Vinay \& Mohit Gupta. (2011). Expansive Soil Stabilization Using Marble Dust. International Journal of Earth Sciences and Engineering. Volume 04.

Al-Huda Nafizah \& Gunawan Hendra. (2013). Pemanfaatan limbah karbit untuk 
meningkatkan nilai CBR tanah lempung Desa Cot Seunong, Konfrensi Nasional Teknik Sipil 7 (KoNTeks), Surakarta, 24-26 Oktober.

Baser Onur. (2009). Stabization of expansive soils using waste marble dust. A thesis submitted to the graduate school of natural and applied sciencesofmiddle east technical university.

Hardiyatmo C. H. (2006). Mekanika Tanah 1. Gadjah Mada University Press, Jakarta.

Hardiyatmo H.C. (2010). Stabilisasi

Tanah Untuk Perkerasan Jalan,

Gajah Mada

University Press, Yogyakarta.

Hasanuddin. (2011). Analisis

Pemakaian Matos Sebagai

Bahan Tambah Pada

Stabilisasi Tanah Lempung

Dengan Kapur. Tesis Program

Magister Teknik Sipil

Universitas Islam Riau.

Sutikno \& Damianto Budi. (2009).

Stabilisasi Tanah Ekspansif Dengan Penambahan Kapur (Lime) Aplikasi Pada pekerjaan Timbunan. Jurnal Teknik sipil dan Perencanaan. Nomor 2 Volume 11.

Wardana I Gusti Ngurah. (2009). Kelakuan Tanah dengan Sifat Kembang Susut yang Tinggi pada Stabilisasi Tanah dengan Bahan Serbuk Marmer dan Bahan Stabilia. Jurnal Ilmiah Teknik Sipil Vol. 13 No.2.

Wiqoyah Qunik. (2006). Pengaruh Kadar Kapur, Waktu perawatan dan Perendaman Terhadap Kuat Dukung Tanah Lempung. Universitas Muhammadiyah Surakarta.
Zulkifli dkk. (2010). Kajian

Laboratorium Limbah Marmer sebagai Filler Dalam Campuran Aspal Beton Lapis Antara (AC-BC).

Zultan Achmad. (2011). Stabilisasi Tanah Dasar Menggunakan Limbah Beton. Tesis Program Pascasarjana Universitas hasanuddin. 